\section{مقاله}

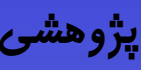

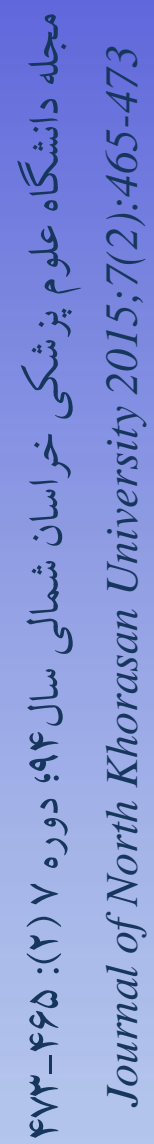

وصول:

اصلاح:

يذيرش: و

\section{ارتباط سندر بيش از قاعدكى و روابط زناشويى زنان كار مند مراكز بهداشتى و در مانى إنى}

\author{
راحله عسلى "'، فاطمه جال مروى '، فرزانه انصارى يور"، حسين لشكردوست"
}

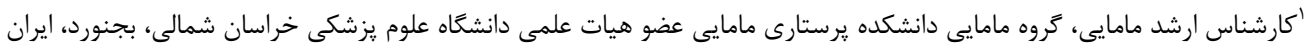

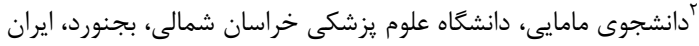

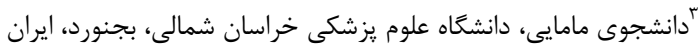

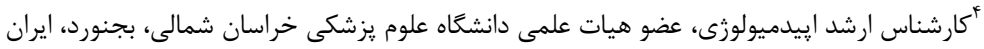

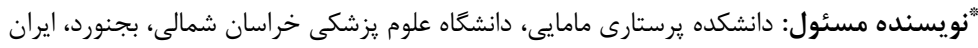

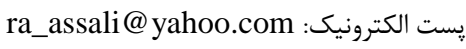

جكيده

زمينه و هدف: سندرم بيش ازقاعدكى ظهور دوره اى يك يا جند علامت /ز مجموعه بزركى /ز علايم، درست قبل

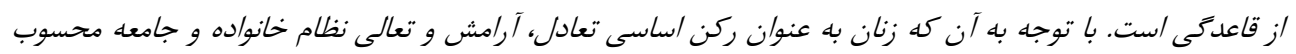

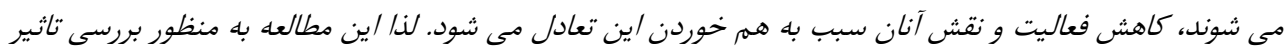

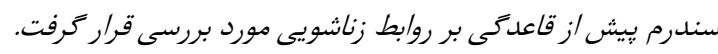

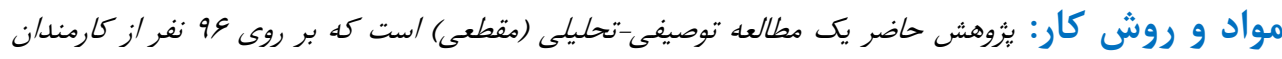

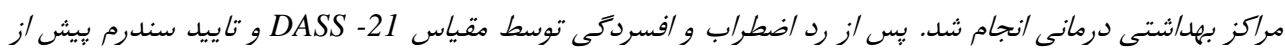

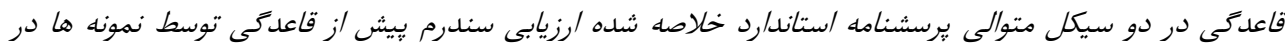

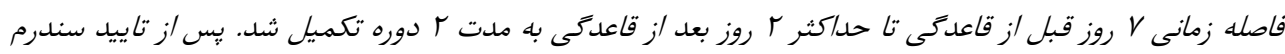

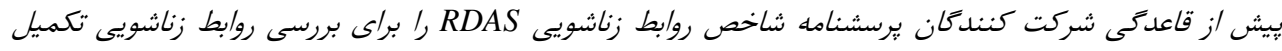
كردند. يافته ها: نتايج مطالعه نشان داد هV/D درصد /فراد مورد مطالعه سندرم بيش /ز قاعدىى خفيف وله درصد متوسط،

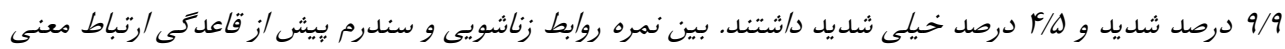

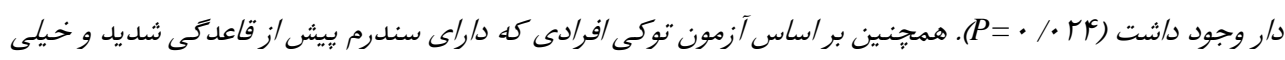

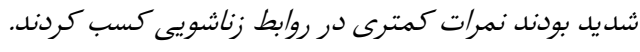

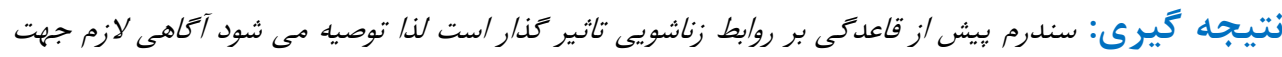

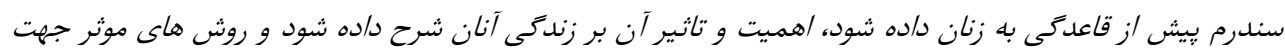

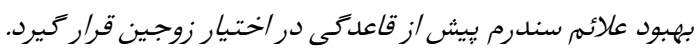
وازه هاى كليدى: سندرم قبل زز قاعدىى، روابط زناشويى، زنان شاغل 
خانم ها با شدت هاى مختلف ديده مى شود و در ه درصد

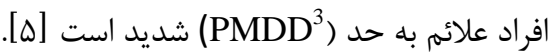

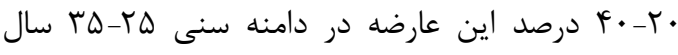

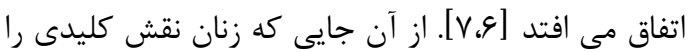

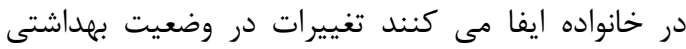

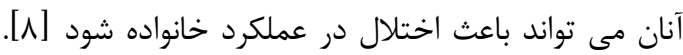

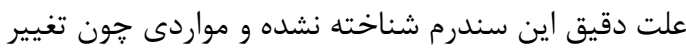
در سطوح استروزن و يروزسترون تغييرات مركزى كاتكول

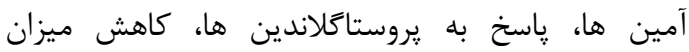
دويامين و سروتونين مركزى ذكر شده كه امروزه بيشتر از

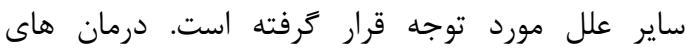

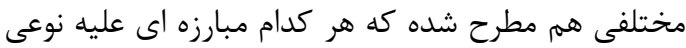

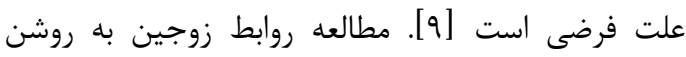
شدن جهارجوب هاى ساختارى كه روابط زوجين در آن

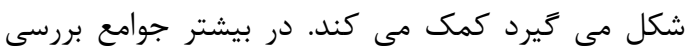

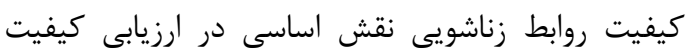

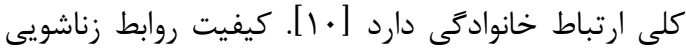
مفهومى جند بعدى است كه شامل: ابعاد كوناكون ارتباط راطيط زوجين مانند: سازكارى، رضايت، شادمانى، انسجام و تعهد

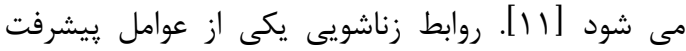

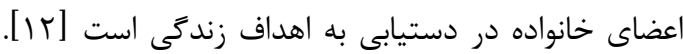

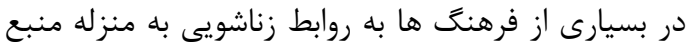

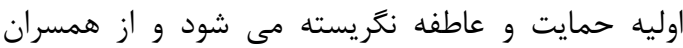
انتظار مى رود تا يك رابطه انحصارى صداقت، علاقه،

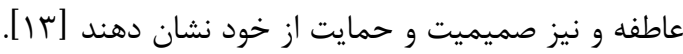
زنان در فاز قبل از قاعدكى دجار اختلالاتى مي شئ شوند كه

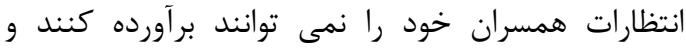

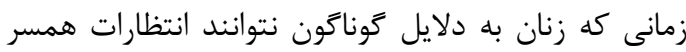

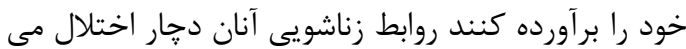

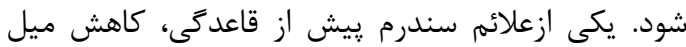

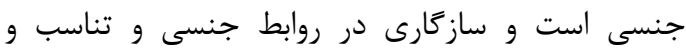
تعادل در مقدار تمايل جنسى در زن و مرد، از مههم ترين علل خوشبختى و موفقيت زندكى زناشويى است. برخى از داز

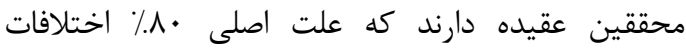

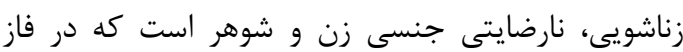
قبل از قاعدگى زنان، موجب اختلال مى شود، از سويى ناسازكارى در روابط زوجين موجب اختلال در در روابط

1-Pre Menstrual Syndrom

2-Late Luteal Phase Dysphoric Disorder 3-premensturaldyphoric disorders

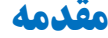

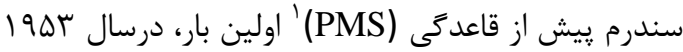

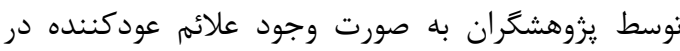

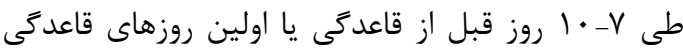

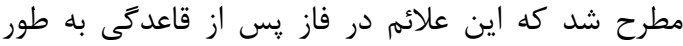

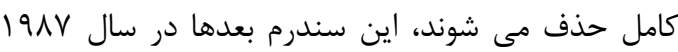

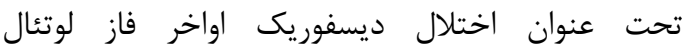
(LLPDD)

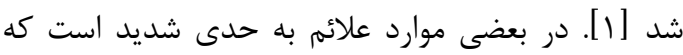
زندكى روزمره را تحت تاثير قرارمى دهد و نياز به درمان بدان

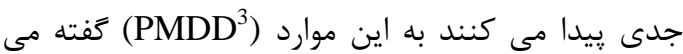
شود [r] اين سندرم با تغييرات دوره اى در وضعيت جسمى، روانى إنى

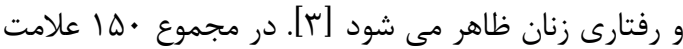
و بيشتر به عنوان علائم اين سندرم شناسايى شده است

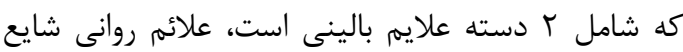
شامل: ضعف، خستكى، تحريك يذيرى و تند مزاجى خلق

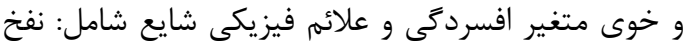

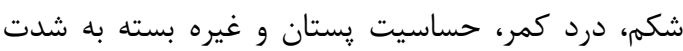
علايم، طيف وسيعى از بيمارى از وضعيت خفيف تا شديد ايجاد مى شود كه اين علائم باعث اختلال در فعاليت هاى إي

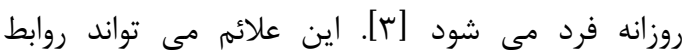
اجتماعى آنان را تحت تاثير قرار دهد، اختلالات خلقى بـ برد روى احساس فرد نسبت به خودش، دنيايى كه در آن آن

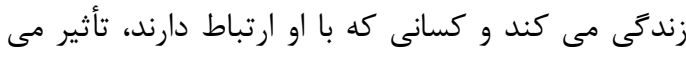
كذارد و با بسيارى از مشكلات مانند: اضطراب و افسردىى همراه است و آمار اقدام به خودكشى در اين افراد اد باد مالاست

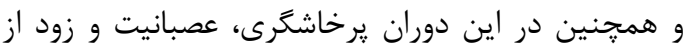

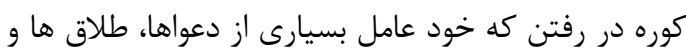

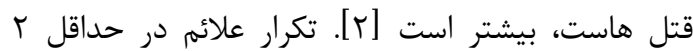

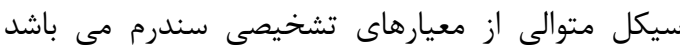

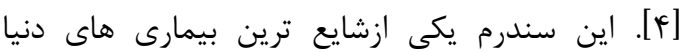
شناخته شده است [1]. از نظر ميزان شيوع در هو در درصد 
ابتدا يرسشنامه ى DASS -21 كه اضطراب، استرس و افسردىى را مى سنجد براى نمونه هاى يزوهش ير شده،

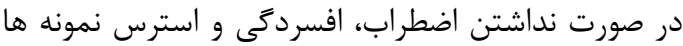

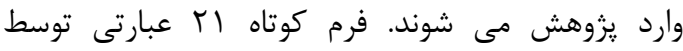

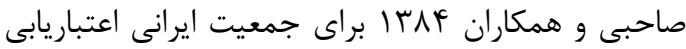

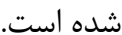

كرافورد و هنرى (r . •r) در نمونه IVYI نفرى انعلستان

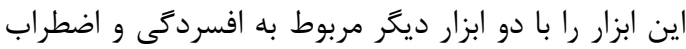

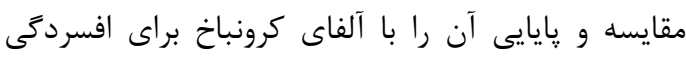

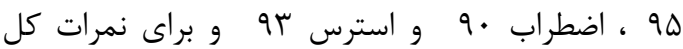
Sزارش نمود. در ايران نيز توسط مرادى يناه، آلفاى

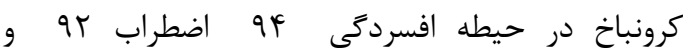

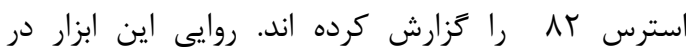
مطالعات متعدد خارجى و داخلى تاييد شده است.

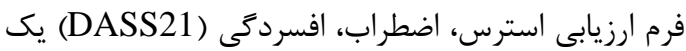

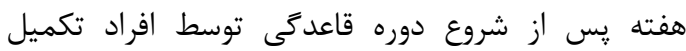

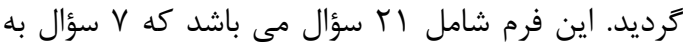
بررسى استرس، V سؤال به بررسى اضطراب و V سؤال به إنه

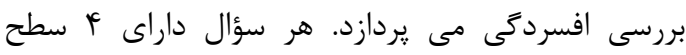

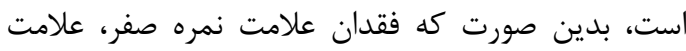
خفيف نمره l، علامت متوسط نمره r و و علامت شديد ندره نمره r دريافت مى كند. در صورت داشتن فرم شديد در هر بخش، فرد مورد نظر از مطالعه خارج مى كرديد. يس

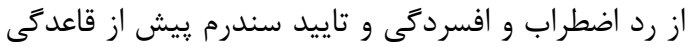

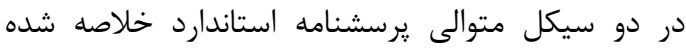
ارزيابى سندرم ييش از قاعدگى توسط نمونه ها در فاصله

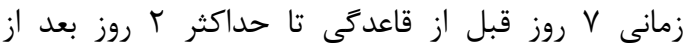

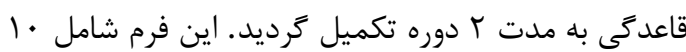

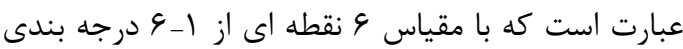

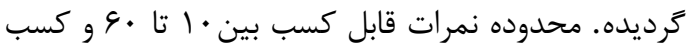

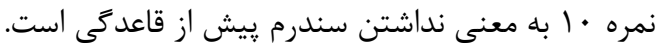

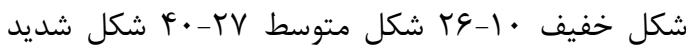

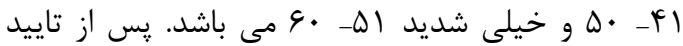
از ابزار شاخص روابط زناشويى PMS

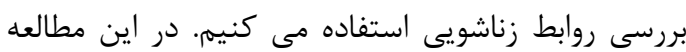
Scale مقياس تجديد نظر شده مقياس ساز كارى دوتائ Revised Dyadic Adjustment
اجتماعى ،كرايش به انحرافات اجتماعى و افول ارزش هاى

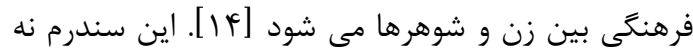

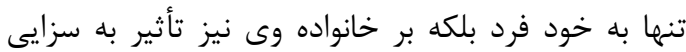

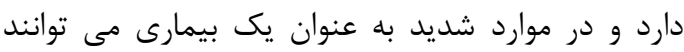
سبب ايجاد تغييراتى در رفتار زنان گردد. نتيجه اين تغيير

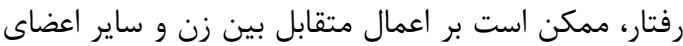
خانواده اثركذاشته و از آن جا كه زنان بنان نقش كليدى دن در

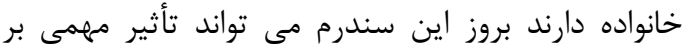

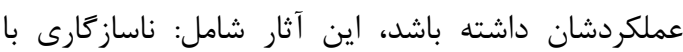

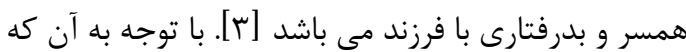
زنان به عنوان ركن اساسى تعادل، آرامش و تعالى نظام

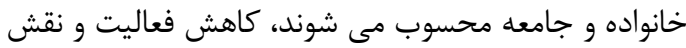

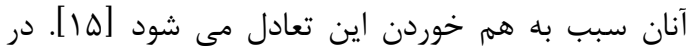

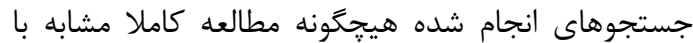
مطالعه حاضر يافت نشد. لذا بر آن شديم تا مطالعه اي بان إنائ

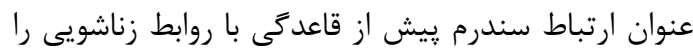

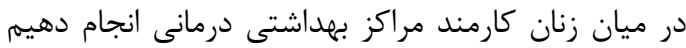
انجام دهيم. اين جامعه يزوهش به علت در دسترس بودن

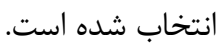

\section{روش كار}

يروهش حاضر بر روى צو نفر ازخانم هاى كارمند مراكز

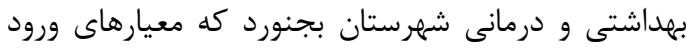
به يزوهش را داشتند، انجام شده است. معيارهاى ورود بهان بهن

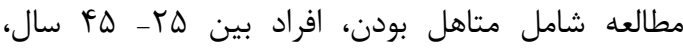

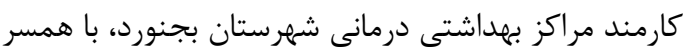

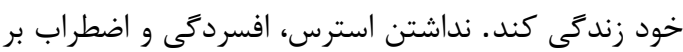
اساس :برسشنامه ى DASS -21 بود. معيارهاى خروج

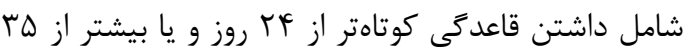

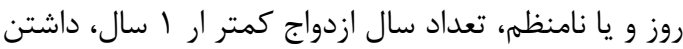
بيمارى صعب العلاج، داشتن بيمارى روانى، ورزشكار بودن،

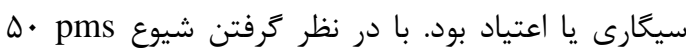

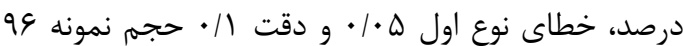
نفر تعيين شد. نمونه گيرى به روش تصادفى ساده انجام

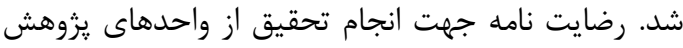

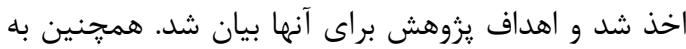
واحد هاى يزوهش در مورد محرمانه ماندن اطلاعات مرتبط با آنها اطمينان داده شد. 
راحله عسلى و همكاران

افراد مشخص شده است. "نمودار r" ميزان تحصيلات

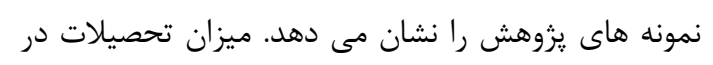

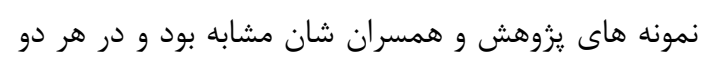

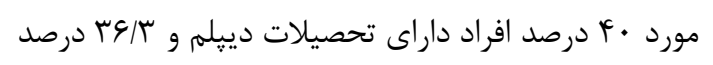

$$
\text { داراى تحصيلات ليسانس مى باشند. }
$$

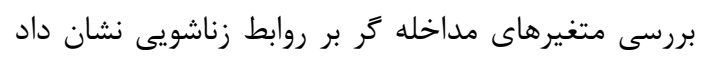

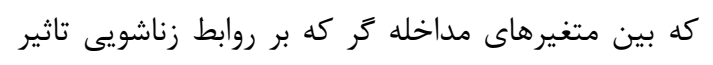

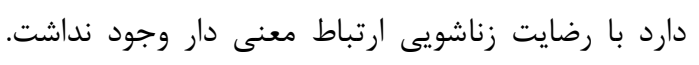

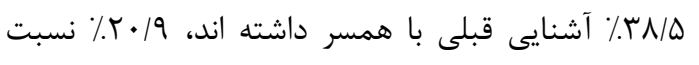
فاميلى با همسر خود داشته، يك مورد داشتن هوو وجود

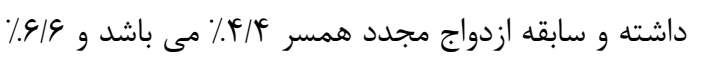
از افراد داراى بيمارى مزمن بوده اند. در "نمودار ا ل "ميزان

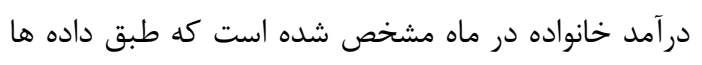

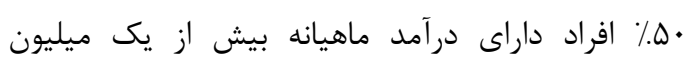
هستند. بين ميزان درآمد و رضايت زناشويى ارتباط وجود نداشت.

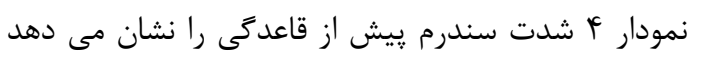
كه، وه. داراى شدت PMS متوسط هستند،

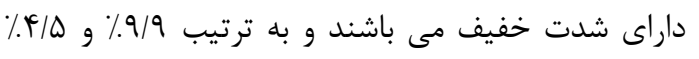

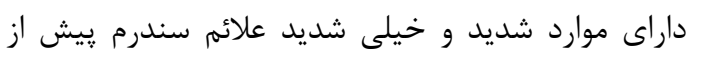
قاعدگى مى باشند. بر اساس جدول ع خ خانم هايى كه

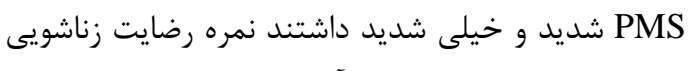

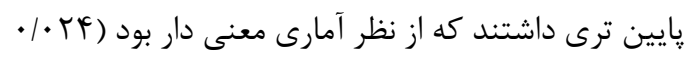
. $(\mathrm{P}=$
1وعزهارتباط سندرم ييش از قاعدگى و روابط زناشويى...

گرفت مقياس سازگارى دوتايى در سال 19V9 توسط

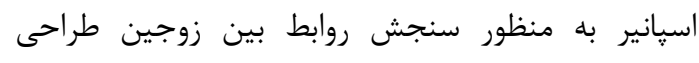
كرديد كه در سال 1999 توسط بابسى و هم كاران مورد

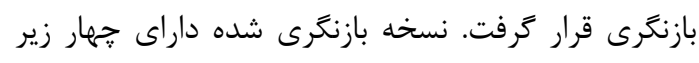
مقياس تفاهم با همسر، بيان عواطف نسبت بله همسر،

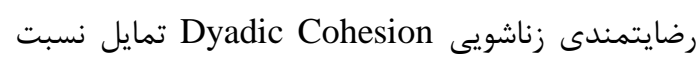

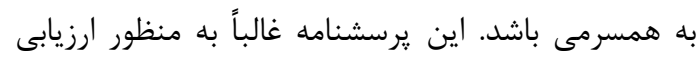

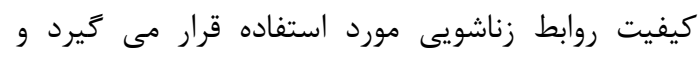

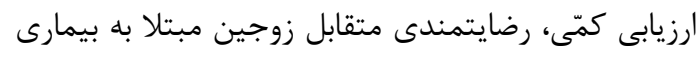

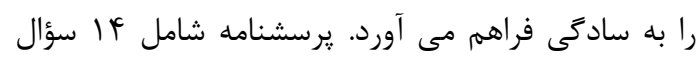
مى باشد كه توافق زوجين در تصميه گيرى ها و رفتارهاى رفي

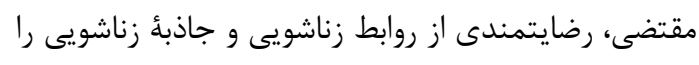

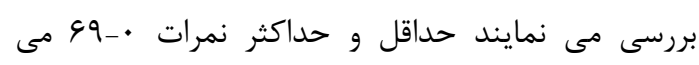
باشند كه نمره كمتر نمايانگر روابط زناشويى نامطلوب

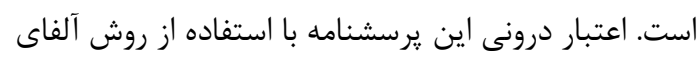

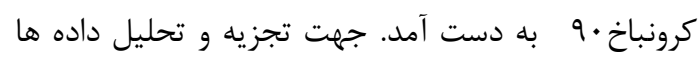

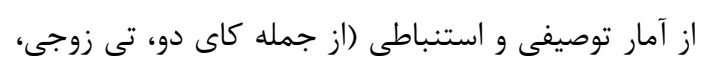
همبستخى) و نرم افزار 18 SPSS استفاده شد.

\section{يافته ها}

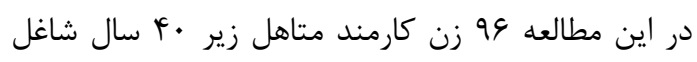

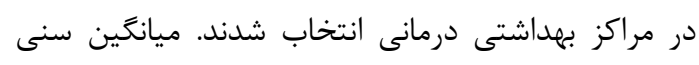

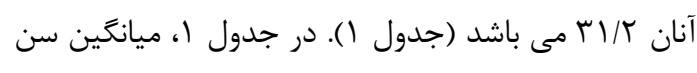
باردارى، سن همسر، تعداد فرزند و نمره رابطه زناشويى

\begin{tabular}{|c|c|}
\hline ميانگين 土 انحراف معيار & متغير هاى توصيفى \\
\hline $1 / F F \pm 1 / \cdot r$ & تعداد فرزند \\
\hline$r \cdot / V \varepsilon \pm q / r V$ & سن اولين باردارى \\
\hline$r \Delta / \Lambda r \pm q / \Delta r$ & سن همسر \\
\hline$r|r| \pm q / r$. & 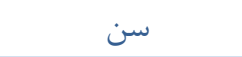 \\
\hline $1 \cdot 9 / V \pm 1 \Lambda / f$ & نمره رابطه زناشويى \\
\hline
\end{tabular}




\begin{tabular}{|c|c|c|c|c|}
\hline & حداكثر & حداقل & ميانكَين & شغل همسر \\
\hline & 99 & Qr & $V \wedge / \Delta \pm r I / 1 I$ & كارگر \\
\hline \multirow[t]{4}{*}{ Tuky* } & Ifr & $V / / \Delta$ & $11 \cdot|q r \pm| r / 9 V$ & كارمند \\
\hline & let & $\Delta \Lambda$ & $1 \cdot G / V T \pm 1 N / A K$ & آزاد \\
\hline & 11. & 11 & $Q V / T r \pm I F / \Lambda F$ & بازنشسته \\
\hline & va $F=r$ & & & \\
\hline
\end{tabular}

جدول سا: ميانگين نمره رابطه زناشويى با شدت PMS

\begin{tabular}{|c|c|c|c|c|}
\hline & حداكثر & حداقل & ميانگين & شدت PMS \\
\hline & IF & $9 \pi$ & $|r| / V V \pm|9| \cdot 9$ & خفيف \\
\hline & Ifr & $8 \Lambda$ & $1 \cdot V / 11 \pm 19 / V \Delta$ & 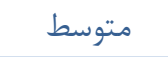 \\
\hline Tuky* & 149 & $\Delta \Lambda$ & $1 \cdot \Delta / F F \pm 1 \& / V D$ & 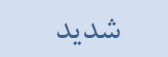 \\
\hline Tuky* & $11 \pi$ & $\Delta r$ & QT/AT \pm Tr/T & خيلى شديد \\
\hline \multicolumn{5}{|c|}{ Anova $\mathrm{F}=r / r r \quad \mathrm{P}=\cdot / \cdot r r$} \\
\hline
\end{tabular}

\begin{tabular}{|c|c|c|c|c|}
\hline حداكثر & حداقل رابطه ز & ميانَّين & تعداد & ميزان تحصيلات \\
\hline ITF & $\Delta \Lambda$ & 91 & V & زيردييلم \\
\hline $1 \pi \Delta$ & VI & $1 . r / 9 r$ & r. & دييلم \\
\hline lfr & $\Delta T$ & $1 \cdot \Delta / \Delta \Delta$ & 1. & فوق دييلم \\
\hline Ifr & $V) / \Delta$ & $111 / \pi$ & rF & ليسانس \\
\hline ITV & $1 \cdot r / Q$ & $119 / \pi$ & $\Delta$ & فوق ليسانس \\
\hline IF & $\Delta T$ & $1.9 / \mathrm{V}$. & 99 & كل \\
\hline \multicolumn{5}{|c|}{ Anova $F=r / F \mid P=\cdot / \cdot \Delta F$} \\
\hline
\end{tabular}



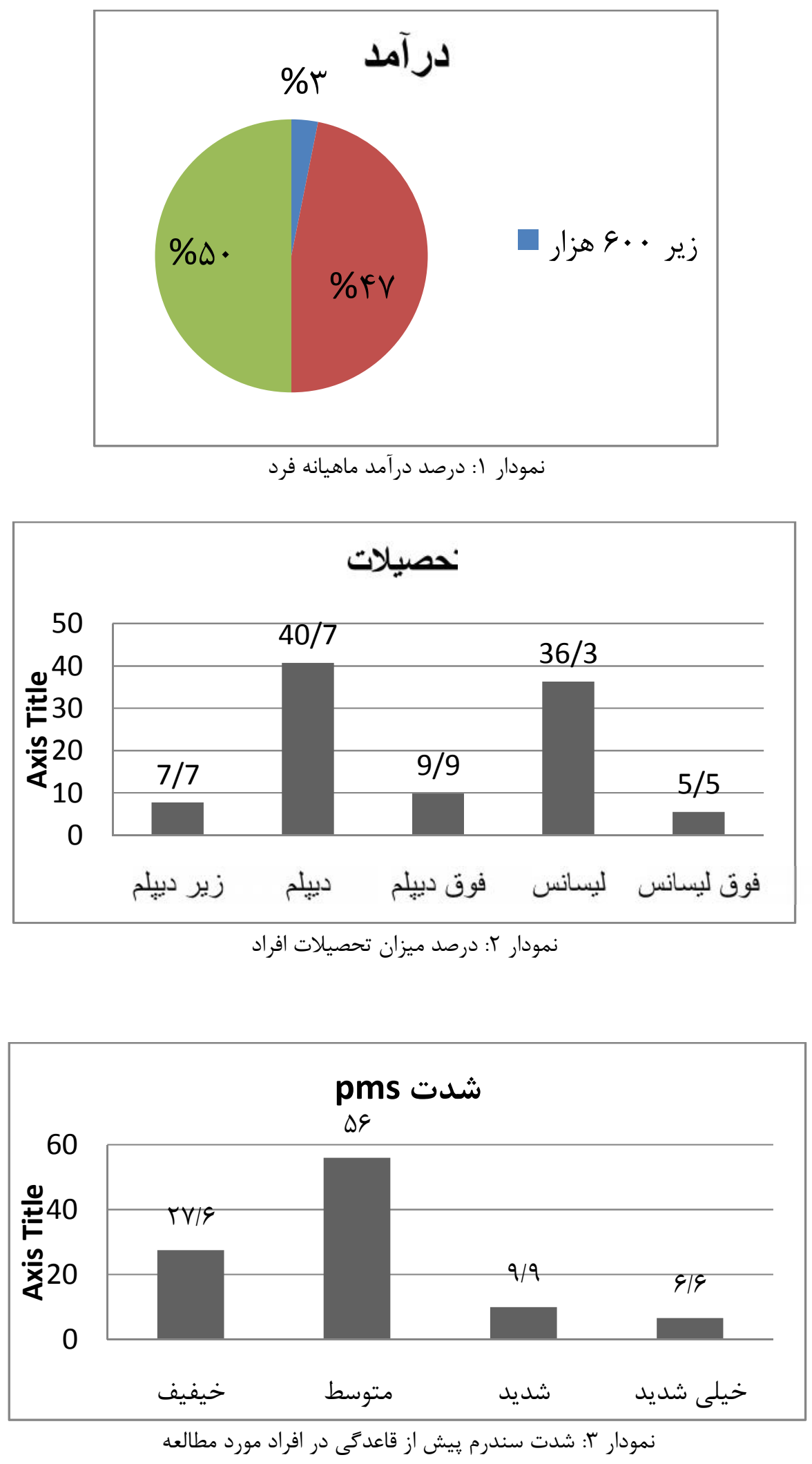
بود، در حالى كه در فاز لوتئال زوجها در روابط خود دجار

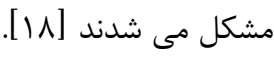

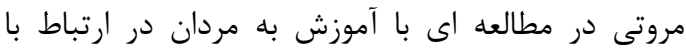

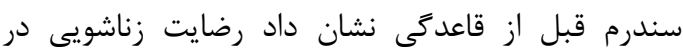

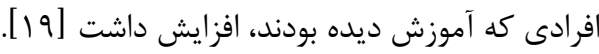
اين مطالعه بر روى زنان شاغل در مراكز بهداشتى انجام

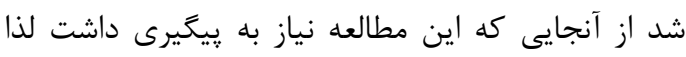

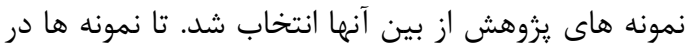
دسترس جهت يِيكيرى باشند. با توجه به اينكه مطالعه

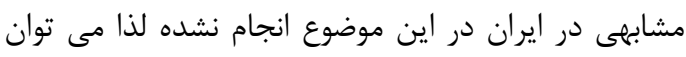

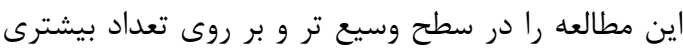

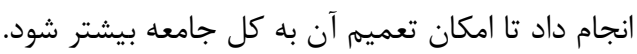

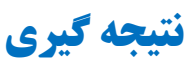

امروزه تامين سلامت زنان به عنوان يكى ازحقوق مسلم

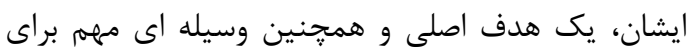

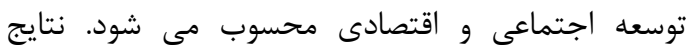

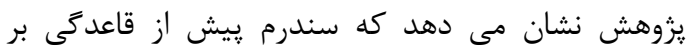

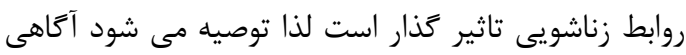

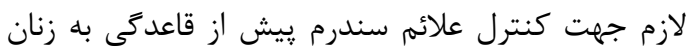

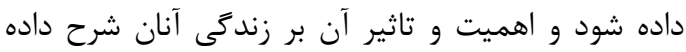

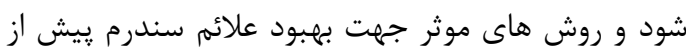
قاعدگى در اختيار زوجين قرار گيرد.

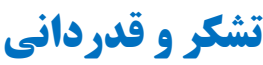

يروهشكران از همكارى معاونت يزوهشى دانشخاه علوم يزشكى خراسان شمالى، كميته تحقيقات دانشجويى، رئي كليه مراكز بهداشتى و درمانى استان خراسان شمالى ودمانى وكليه واحدهاى يزوهش قدردانى و تشكر مى شود اين طرح بانيان

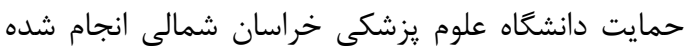

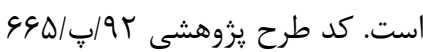

نتايج اين مطالعه نشان داد كه بين سندرم پِيش از

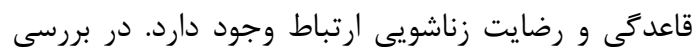

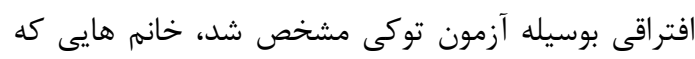

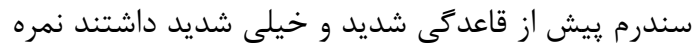
رضايت زناشويى پايين ترى داشتند (جدول بآ). در موارد

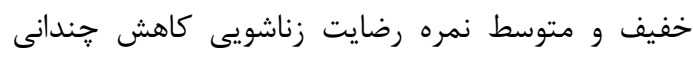

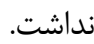
بين شغل همسر و رضايت زناشويى ارتباط آمارى معنى

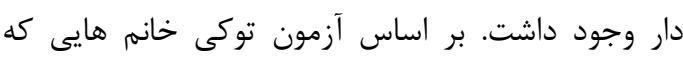
همسرانشان كارمند بودند نمره رضايت زناشويى بالاتئ آترى

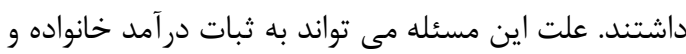

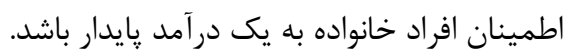
ميانگين نمره رابطه زناشويى در خانم هايى كه همسرشان

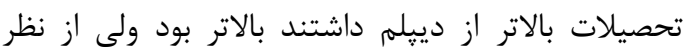
آمارى معنى دار نبود (جدول عالاتر). در مطالعه اميرى شيوع فراوانى اين سندرم در نمونه هاى نداى يروهش بر اساس شدت علايم: خفيف، متوسط، شديد و ورئ

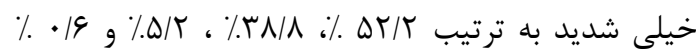
مى باشد كه شيوع موارد شديد و خيلى شديد مشابه مطالعه حاضر مى باشد [ب]. در مطالعه دل آرا شدت علايم و تداخل علايم با فعاليت إليت هاى اجتماعى و تحصيلى با مرحله تصميم گيرى فرد همبستكى مثبتى حاصل شد. در مطالعه حاضر نيز در

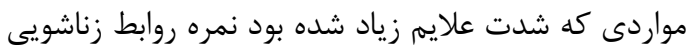

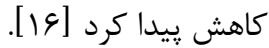
مطالعه مروان نشان داد روابط زناشويى در دوره قبل ازداز

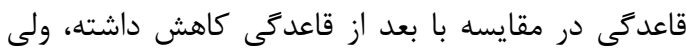

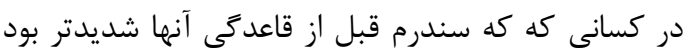
روابط زناشويى بشدت كاهش يافت [IV]

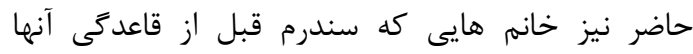
شديدتر بود نمره رضايت زناشويى كمايى كمترى داشدرم داشتند.

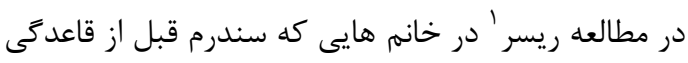

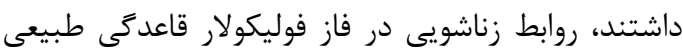

\section{1-Ryser}




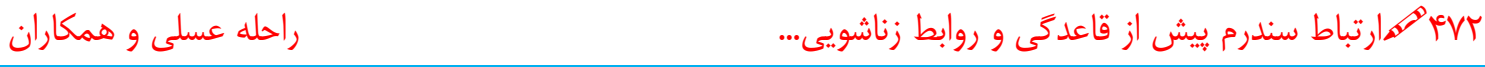

References

1. Azgoly G, Shahvh M, Ismaili S, Nasiri N, Edible oil of orange peel effect on the severity of symptoms of premenstrual syndrome, double-blind, placebo-controlled clinical trial, Journal of Reproduction and Infertility, Spring 2011;12(2) :129-123[Persian].

2. Mahmudi Z, Shahpourian F, bastani F, parsai S, Hosseini F, The effect of adding carbohydrate diet in the form of food supplements on the severity of premenstrual syndrome, Improve the fourteenth year, Journal of Kermanshah University of Medical Sciences, Spring 2010;14(1):10-19[Persian].

3. Amir FarahaniL, Haidari T, naranji F, asghariJafarabadi M, Shirazi V, Relationship between body mass index in female students with premenstrual syndrome, Journal of Nursing and Midwifery, (Life), 2011; 17(4):85-95[Persian].

4. Rajaeyan A, Noorshahi M, Zahedi H, The relationship between the incidence of premenstrual syndrome with power, aerobic female athletes and non-athletes, Iranina Journal of Obstetrics Gynecology and Infertility, 2011;14:16-25

5. Akhlaghi F, hamedi A, Javadi Z, Hosseinipur F, Effects of calcium supplementation on premenstrual syndrome, Iranian University of Medical Sciences Journal, 669, Winter 2004:10(37):669-676[Persian].

6. Dickerson LM, Mazyck PJ, Hunter MH, Premenstural syndrome, Am Fam Physician 2003 67(8):1743-52.

7. Rapkin AJ, New treatment approaches for premenstrual disorders, Am J Manage Care 2005;11 : 480-91.

8. Karimiyan N, Rezaeian M, nasaji F, valaiin,gachkar L, Effect of Exercise on Premenstrual Syndrome. Zanjan University of Medical Sciences, 2007; 13(53): 8-15[Persian].

9. SperoffL,Fritz MA, Clinical gynecologic endocrinology and infertility, $7^{\text {th }}$ ed. Philadelphia :Lippincott Williams \&Wilkins,2005;p.531-46.

10.Eisanejad A, Ahmadi A, etemadi A,The effectiveness of enriching relationships on improving the quality of marital relationships, Journal of Behavioral Sciences, Spring 2010; 4(1): 9-16.

11.Yousefi N, Sohrabi A, Compare the effectiveness of family therapy approaches based on marital quality in the presence of mind and metacognition clients on the verge of divorce, Journal of mental health counseling, family, Fall 2011;1(2): 211-192[Persian].

12.Navabinejad SH,malek A ,Effectiveness of certain combat-oriented thinking on improving marital relations, Thought and Practice, Summer 2010;4(16):570-746[Persian].

13.Azkhosh M, Asgari A, Measuring irrational beliefs in the marital standard of communication Beliefs Questionnaire, Iranian Psychological Journal, Winter2008;14: 263-280[Persian].

14.Nurani SH ,Joneidi A, Shakeri M, Mokhber N, Compare sexual satisfaction in fertile and infertile women referred to the government center in Mashhad, Journal of Reproduction and Infertility, Volume 10, Number 4, Winter 2010;10(4):277-269[Persian].

15.sheikheslami R, nejati A, ahmadi S, Forecasting component of married women through selfesteem and marital happiness, Women in Culture and Arts, Fall2011;3(1): 39-54[Persian].

16.Delara M, Ghofranipour F, Azad Fallah P, Tavafian SS, Kazemnejad A, Decision Making Process and Related Factors in Adolescents with Premenstrual Syndrome, Quarterly Journal of Sabzevar University of Medical Sciences,2012 Spring ;19( 1):59-68[Persian].

17.Marván ML, MartínezMillán ML,Marital communication and premenstrual symptoms,

ActaPsiquiatrPsicol Am Lat. 1995 Mar;41(1):24-8.

18.Ryser R, Feinauer, Premenstrual syndrome and the marital relationship, The American Journal of Family Therapy,1992;20(2):179-190(Published online: 13 Jun 2007.

19.MorowatiSharifabad MA, Karimiankakolaki Z, Bokaei M, Fallahzadeh H, Mirrezaii S, Frequency of Marital Dissatisfaction in Couples With Wives Who Suffer From Premenstrual Syndrome in The City of Yazd, J Health Syst Res 2014; 10(2):315-325[Persian]. 


\title{
Premenstrual syndrome and the marital relationship
}

\author{
Assali $R^{l}$, Jalal Marvi $F^{2}$, Ansari $F^{3}$, Lashkardost $H^{4}$
}

${ }^{1}$ Faculty member of North Khorasan University of Medical Sciences .Nursing and Midwifery Faculty. Midwifery department,Bojnurd, Iran

${ }^{2}$ Midwifery Student, North Khorasan University of Medical Sciences,Bojnurd, Iran

${ }^{3}$ Midwifery Student, North Khorasan University of Medical Sciences,Bojnurd, Iran

${ }^{4}$ Faculty member of North Khorasan University of Medical Sciences. Health Faculty ,Bojnurd, Iran

*Corresponding Author: North Khorasan University of Medical Sciences, Bojnurd, Iran Emil: ra_assali@yahoo.com

\section{Abstract}

Background \& Objectives: Premenstrual syndrome is existence of one or more symptom and sign from a large collection of signs, before menstruation. Given the role of women in family stability and peace, any decrease in their pivotal activity or emotional disturbance could affect this balance. The aim of this study was to investigate the effects of premenstrual syndrome on marital relations.

Materials and Methods: This cross sectional study was carried out on 96 employed women in health centers. Anxiety, stress and depression were rolled out with DASS -21 scales. Premenstrual syndrome was confirmed with short questionnaire PMS within 7 days before menstrual phase and 2 days after menstrual phase for two menstrual periods. Marital relationship of cases with premenstrual syndrome diagnosis was assessed by RDAS questionnaire.

Results: The results showed $27.5 \%$ of cases were of mild premenstrual syndrome, $56 \%$ moderate, $9.9 \%$ severe, and 5.4 percent were severe. The relationship between marital relationship and premenstrual syndrome was significant $(P=$ 0.024). According Tukey test women with severe and very severe premenstrual syndrome received lower marks in marital relationship.

Conclusions: Premenstrual syndrome could affect marital relationship, so it is recommended that women with premenstrual syndrome receive the necessary knowledge about its effects on their life and effective method to improve the symptoms.

Keywords: Employed women, premenstrual syndrome, marital relationship

Recivied:13 Jul 2015

Revised: 27 Aug 2015

Accepted: 6 Sep 2015 